\title{
Aripiprazole in the Treatment of Refractory Mood Disorders: A Case Series
}

\author{
Ather Muneer \\ Department of Psychiatry, Islamic International Medical College, Pakistan Railway Teaching Hospital, Rawalpindi, Pakistan
}

\begin{abstract}
Major depressive disorder and bipolar disorders are among the commonest neuropsychiatric conditions, affecting persons of both sexes which belong to all age groups. Comorbidity is the rule rather than the exception; anxiety spectrum disorders, somatoform disorders, eating disorders and substance use disorders frequently co-exist with mood disorders. Catatonia is a serious complication of the latter and every patient with a severe affective exacerbation should be assessed for the presence of catatonic signs and symptoms. In a significant minority of patients, symptoms show treatment resistance; many patients experience severe hopelessness and suicidal ideation, causing high rates of morbidity and mortality in afflicted individuals. Pharmacological management is challenging and currently available psychotropic agents often fall short of inducing remission. Second generation antipsychotics have been shown in a number of studies as having an antidepressant and mood stabilizing effect. Aripiprazole is a novel antipsychotic which is being increasingly used in difficult to treat mood disorders patients. Several controlled and uncontrolled studies have shown the efficacy and safety of this medication in subjects of all ages. Here a case series of three patients is presented who suffered from refractory mood disorders but responded to aripiprazole with complete remission of affective symptoms.
\end{abstract}

KEY WORDS: Bipolar disorder; Major depressive disorder; Atypical antipsychotic agents; Aripiprazole.

\section{INTRODUCTION}

Mood disorders are among the commonest conditions presenting to psychiatrists for diagnosis and management. ${ }^{1)}$ Major depressive disorder and bipolar disorders carry high rates of morbidity and mortality. ${ }^{2)}$ Modern psychopharmacological agents often fall short of inducing remission and complex drug regimens are frequently needed to achieve symptom control. ${ }^{3)}$ The past decade has witnessed an increase in the armamentarium of psychotropic medications for the treatment of mood disorders. Second generation antipsychotics are gaining prominence in this respect; however, these agents have pharmacodynamic and pharmacokinetic properties which set these apart and patients often show differential response to each of these medications. ${ }^{4)}$

Aripiprazole is an atypical antipsychotic which was first approved for the treatment of acute schizophrenia; latter it was found effective in the manic and mixed epi-

\footnotetext{
Received: September 26, 2013 / Revised: January 3, 2014

Accepted: January 6, 2014

Address for correspondence: Ather Muneer, MD

Department of Psychiatry, Islamic International Medical College,

Pakistan Railway Teaching Hospital, Rawalpindi, Pakistan

Tel: +92-51-4433097, Fax: +92-51-512-5170

E-mail: muneerather2@gmail.com
}

sodes of bipolar disorder type I. ${ }^{5)}$ More recently the drug received US Food and Drug Administraion approval for the treatment of major depressive disorder. ${ }^{6)}$ There is emerging evidence for the efficacy of aripiprazole in refractory mood states. ${ }^{7)}$ Here a case series of three patients is presented who were only having partial benefit from their drug regimen but achieved remission with the help of aripiprazole. All of these patients were seen in the outpatients' psychiatry clinic of Pakistan Railway Teaching Hospital, Rawalpindi, an academic unit affiliated with Islamic International Medical College.

\section{CASE}

\section{Case 1}

A 15 years old girl presented to the outpatients' clinic accompanied with her aunt; her primary complaint was that her left arm was hurting and she was unable to move it. These symptoms started about 4 weeks ago and gradually increased in severity until there was no function left in the affected arm. She denied any conflict or stressor prior to the onset of symptoms; further psychiatric evaluation revealed that she had a low mood with loss of pleasure in day to day activities. She had a decreased appetite with initial and middle insomnia, diminished energy and easy fati-

(c) This is an Open-Access article distributed under the terms of the Creative Commons Attribution Non-Commercial License (http://creativecommons.org/licenses/by-nc/3.0) which permits unrestricted non-commercial use, distribution, and reproduction in any medium, provided the original work is properly cited. 
gability. She expressed ideas of reduced self worth and helplessness but denied having suicidal ideation. She also had severe irritability and increased interpersonal sensitivity. Physical examination including a detailed neurological examinational was completely normal.

She was diagnosed as suffering from conversion disorder with comorbid major depressive disorder with mixed features according to the Diagnostic and Statistical Manual of Mental Disorders, fifth edition (DSM-5; American Psychiatric Association, May 2013). Psychopharmacological treatment was started and consisted of escitalopram $10 \mathrm{mg} / \mathrm{d}$, mirtazapine $30 \mathrm{mg} / \mathrm{d}$, and levetiracetam $1,500 \mathrm{mg} / \mathrm{d}$. She was seen regularly on a weekly basis and supportive psychotherapy and physiotherapy sessions were also included. The first 6 weeks resulted in modest progress with improvement in sleep, some relief of depression, decreased pain in the affected arm with increased range of motion. However, in the next 4 weeks the patient had anxiety and restlessness with mood lability and her progress stalled. At this stage aripiprazole was introduced in a dose of $10 \mathrm{mg} / \mathrm{d}$ and in the following 3 to 4 weeks there was a remarkable betterment in her condition with remission of the depressed mood and almost complete return of function of the left arm with only minor residual pain on full motion. The period of follow-up was increased to once every 3 weeks and the following medications were continued to maintain the remission phase of the mood disorder: 1) Aripiprazole $10 \mathrm{mg} / \mathrm{d}$; 2) Escitalopram $10 \mathrm{mg} / \mathrm{d}$; 3) Mirtazapine $30 \mathrm{mg} / \mathrm{d}$; 4) Levetiracetam $1,500 \mathrm{mg} / \mathrm{d}$.

\section{Case 2}

A 50 years old woman presented herself to the psychiatry clinic accompanied with her husband. She was a known case of bipolar affective disorder and suffered from frequent mood episodes with brief periods of remission. She was taking 2 mood stabilizers - carbamazepine and divalproex sodium but her condition was deteriorating as she was becoming very lethargic and spending increasing periods in bed. She was not taking proper care of herself with decline in self grooming and personal hygiene and a decrease in social interaction with others. She showed indecisiveness, ambivalence and negativistic behavior. She also had decreased food intake and severe insomnia. Mental state examination revealed psychomotor retardation, prolonged staring, posturing, decreased rate, rhythm and volume of speech, waxy flexibility and catalepsy. She was diagnosed with bipolar disorder type I, current episode depressed with catatonic features.
Electroconvulsive therapy was suggested but both the patient and her husband refused to give permission for this treatment. As such it was decided to try a novel anticonvulsant, i.e., levetiracetam in place of carbamazepine and divalproex sodium. In addition alprazolam $1 \mathrm{mg}$ at night was used for insomnia. The patient's catatonic state showed response to this strategy and there was significant improvement within 6-8 weeks, however, she remained lethargic with poor social and occupational functioning, decreased self grooming and lack of interest in day to day activities. Aripiprazole was introduced in a dose of 15 $\mathrm{mg} / \mathrm{d}$ and after another 8 weeks there was complete symptomatic improvement and remission. At this stage her medications included: 1) Aripiprazole $15 \mathrm{mg} / \mathrm{d}$; 2) Levetiracetam $1,500 \mathrm{mg} / \mathrm{d}$; 3) Quetiapine $100 \mathrm{mg}$ every night at bedtime.

She was advised to continue taking these medications to maintain the remission phase of bipolar disorder and attend the clinic for regular follow-ups.

\section{Case 3}

An 18 years old girl was brought to the psychiatry clinic by her father. She was over active, over talkative with pressure of speech and flight of ideas. Her mood was elated and she had grandiose ideation; she also showed over familiarity and distractibility and her sleep was reduced to only a few hours/day. The patient's condition had been like this for the past several weeks; however, the family was coping with her condition somehow. At the initial visit a review of the records revealed that she had similar episodes in the past and was diagnosed as a patient of bipolar affective disorder. She had bipolar disorder type I, current episode manic without psychotic features. Pharmacotherapy was initiated with risperidone $6 \mathrm{mg} / \mathrm{d}$, divalproex sodium $1,000 \mathrm{mg} / \mathrm{d}$ and alprazolam $2 \mathrm{mg} / \mathrm{d}$. The patient showed only partial response to this drug regimen and 8 weeks after start of treatment risperidone was replaced with aripiprazole which was administered in a single daily dose of $15 \mathrm{mg}$. Two weeks later the patient's mania resolved completely, but remission was not achieved as a severe anxiety state became evident. Gabapentin was initiated in a total daily dose of $900 \mathrm{mg} / \mathrm{d}$ and after a further period of 2 weeks the patient achieved remission with relief from anxiety and a euthymic mood. At this point her medications consisted of: 1) Aripiprazole $15 \mathrm{mg} / \mathrm{d} ; 2$ ) Divalproex sodium 1,000 mg/d; 3) Gabapentin 900 mg/d; 4) Alprazolam $1 \mathrm{mg} / \mathrm{d}$.

She was advised to continue taking these medications to maintain remission and have periodic follow-ups. 


\section{DISCUSSION}

This case series illustrates the intricacy of treatment decision making when managing patients with major depressive disorder and bipolar disorders. ${ }^{8,9)}$ In the quest of achieving remission and relieving patients of their symptoms, the treating physician has to keep a number of things in his mind. Firstly, the initial choice of medications should be such that patient tolerability and safety issues receive precedence; secondly, drugs are tailored according to the manifest symptoms and finally, the psychotropic agents have proven efficacy in the treatment of different manifestations of mood disorders. ${ }^{10)}$

Aripiprazole has a novel mechanism of action among atypical antipsychotics; it acts as a partial agonist at dopamine D2 and serotonin $5 \mathrm{HT}_{1 \mathrm{~A}} \mathrm{CNS}$ receptors while antagonizing $5 \mathrm{HT}_{2 \mathrm{~A}}$ receptors. ${ }^{11)}$ It causes fewer extra pyramidal side effects and has a lower incidence of hyperprolactinemia as compared to some of the other second generation antipsychotics, for example, risperidone. ${ }^{12)}$ It is weight neutral, in contrast, to drugs like olanzapine and quetiapine which have the liability to cause the metabolic syndrome. ${ }^{13)}$ It exerts antianxiety and antidepressant effects and does not cause sedation. ${ }^{14)}$ It has a long half life of approximately 75 hours and needs to be administered once daily with steady state levels being achieved in 10 to 14 days. ${ }^{15)}$ An agent with a notable safety profile, emerging evidence supports the use of aripiprazole in resistant mood disorder patients. ${ }^{16,17)}$

In major depressive disorder and bipolar disorders, symptoms sometimes show refractoriness in spite of best attempts at treatment. In the management of such cases patient safety and tolerability issues take priority and psychotropic agents with established effectiveness must be used. Aripiprazole is increasingly being used in patients with intractable mood states caused by such complications as comorbid neuropsychiatric conditions and unresponsive affective symptoms. In this respect, aripiprazole is a valuable agent with high efficacy and patient acceptability.

\section{REFERENCES}

1. Luca M, Prossimo G, Messina V, Luca A, Romeo S, Calandra C. Epidemiology and treatment of mood disorders in a day hospital setting from 1996 to 2007: an Italian study. Neuropsychiatr Dis Treat 2013;9:169-176.
2. Amital D, Fostick L, Silberman A, Calati R, Spindelegger $\mathrm{C}$, Serretti A, et al. Physical co-morbidity among treatment resistant $v$ s. treatment responsive patients with major depressive disorder. Eur Neuropsychopharmacol 2013;23: 895-901.

3. Sienaert P, Lambrichts L, Dols A, De Fruyt J. Evidencebased treatment strategies for treatment-resistant bipolar depression: a systematic review. Bipolar Disord 2013;15: 61-69.

4. Vieta E, Valentí M. Pharmacological management of bipolar depression: acute treatment, maintenance, and prophylaxis. CNS Drugs 2013;27:515-529.

5. de Bartolomeis A, Perugi G. Combination of aripiprazole with mood stabilizers for the treatment of bipolar disorder: from acute mania to long-term maintenance. Expert Opin Pharmacother 2012;13:2027-2036.

6. Nelson JC, Mankoski R, Baker RA, Carlson BX, Eudicone $\mathrm{JM}$, Pikalov A, et al. Effects of aripiprazole adjunctive to standard antidepressant treatment on the core symptoms of depression: a post-hoc, pooled analysis of two large, placebo-controlled studies. J Affect Disord 2010;120:133140.

7. Dording C, Cassiello C, King F 4th, Pencina M, Fava M, Mischoulon D. The effects of aripiprazole on the subscales of the Kellner Symptom Questionnaire in treatment resistant depression. Int Clin Psychopharmacol 2013;28:238-244.

8. Joshi G, Wilens T. Comorbidity in pediatric bipolar disorder. Child Adolesc Psychiatr Clin N Am 2009;18: 291-319.

9. Belaizi M, Yahia A, Mehssani J, Bouchikhi Idrissi ML, Bichra MZ. Acute catatonia: Questions, diagnosis and prognostics, and the place of atypical antipsychotics. Encephale 2013;39:224-231.

10. Geddes JR, Miklowitz DJ. Treatment of bipolar disorder. Lancet 2013;381:1672-1682.

11. Vergne DE, Anton RF. Aripiprazole: a drug with a novel mechanism of action and possible efficacy for alcohol dependence. CNS Neurol Disord Drug Targets 2010;9:50-54.

12. Ziadi Trives M, Bonete Llácer JM, García Escudero MA, Martínez Pastor CJ. Effect of the addition of aripiprazole on hyperprolactinemia associated with risperidone long-acting injection. J Clin Psychopharmacol 2013;33:538-541.

13. Caccia S. Safety and pharmacokinetics of atypical antipsychotics in children and adolescents. Paediatr Drugs 2013;15:217-233.

14. Katzman MA. Aripiprazole: a clinical review of its use for the treatment of anxiety disorders and anxiety as a comorbidity in mental illness. J Affect Disord 2011;128(Suppl 1):S11-S20.

15. Kinghorn WA, McEvoy JP. Aripiprazole: pharmacology, efficacy, safety and tolerability. Expert Rev Neurother 2005; 5:297-307.

16. Fountoulakis KN. Refractoriness in bipolar disorder: definitions and evidence-based treatment. CNS Neurosci Ther 2012; 18:227-237.

17. Blier P, Blondeau C. Neurobiological bases and clinical aspects of the use of aripiprazole in treatment-resistant major depressive disorder. J Affect Disord 2011;128(Suppl 1): $S 3-S 10$. 